\title{
Corticosteroids and ICU Course of Community Acquired Pneumonia in Egyptian Settings
}

\author{
Nirmeen A. Sabry ${ }^{1}$, Emad El-Din Omar ${ }^{2}$ \\ ${ }^{1}$ Clinical Pharmacy Department, Faculty of Pharmacy, Cairo University, Cairo, Egypt; ${ }^{2}$ Department of Critical Care Medicine, Fac- \\ ulty of Medicine, Cairo University, Cairo, Egypt. \\ Email: papers.sabry@gmail.com \\ Received February $2^{\text {nd }}, 2011$; revised February 12 $2^{\text {th }}, 2011$; accepted February $21^{\text {st }}, 2011$.
}

\begin{abstract}
Background: Pneumonia is the most common cause of community-acquired infection requiring ICU admission. $60 \%$ $87 \%$ of patients with severe community acquired pneumonia (CAP) admitted to the ICU develops respiratory failure and require mechanical ventilation (MV). Objectives: To assess the efficacy and safety of adjunctive low dose hydrocortisone infusion treatment in Egyptian ICU patients with CAP. Methods: Hospitalized patients, clinically and radiologically diagnosed with CAP, were randomized to receive hydrocortisone $12.5 \mathrm{mg} / \mathrm{h}$ IV infusion for 7 days or placebo, along with antibiotics. The end-points of the study were improvement in $\mathrm{PaO}_{2}: \mathrm{FIO}_{2}\left(\mathrm{PaO}_{2}: \mathrm{FIO}_{2}>300\right.$ or $\geq 100$ increase from study entry) and SOFA score by study day 8 and the development of delayed septic shock. Results: 80 patients were recruited, 40 of them received hydrocortisone and the remaining 40 received placebo. By study day 8 , hydrocortisone treated patients showed a significant improvement in $\mathrm{PaO}_{2}: \mathrm{FIO}_{2}$ and chest radiograph score, and a significant reduction in C-reactive protein (CRP) levels, Sepsis-related Organ Failure Assessment (SOFA) score, and delayed septic shock compared to the control group. Hydrocortisone treatment was associated with a significant reduction in the duration of MV. However, hydrocortisone infusion did not show significant difference in the ICU mortality. Conclusions: adjunctive 7-day course of low dose hydrocortisone IV in patients with CAP hastens recovery of pneumonia and prevents the development of sepsis related complications with a significant reduction in duration of the mechanical ventilation.
\end{abstract}

Keywords: Community-Acquired Pneumonia, Corticosteroids, Hydrocortisone, Pneumonia

\section{Introduction}

Community acquired pneumonia (CAP), which is a very common reason for hospital admission, represents a potentially life-threatening condition [1]. CAP is the first infectious cause of death in developed countries [2], with an estimate of $10 \%-25 \%$ of CAP patients do not cure in a timely manner [3]. The main reasons behind this delay are: 1) development of complications e.g., post-obstructive pneumonia, empyema, or lung abscess; 2) false perception of treatment failure. This perception may be attributed to the slow recovery in patients have superimposed problems, e.g., malignancy, inflammations, heart failure, or hospital-acquired infection [4].

Patients diagnosed with severe CAP normally require admission to intensive care unit (ICU). More than 50\% of the patients admitted to the ICU develop respiratory failure and require mechanical ventilation (MV) with a high mortality rate [5].

Several studies have shown increased pulmonary and circulating inflammatory cytokine levels in patients with severe CAP [6-9]. The levels of these mediators were strongly associated with the presence of pneumonia [6], bacteremia, and need for MV [7], Acute Physiology and Chronic Health Evaluation (APACHE) II and multiple organ dysfunction syndrome (MODS) scores $[6,8,9]$. It was shown that there is a direct correlation between CAP's severity and the levels of circulating inflammatory cytokines in CAP patients [6-8,10].

One of the main factors controlling the progression of pneumonia is the host inflammatory response, which increases excessively in non-responding pneumonia [11,12].

Many researchers were highly motivated to study the relationship between host response and the level of stress. These studies had a great focus on the role of intact hypothalamic-pituitary-adrenal response to prevent the dissemination of pro-inflammatory storm from one organ to another following local infection [13].

Corticosteroids, the most important natural inhibitors of inflammation, are not always effective in suppressing 
life-threatening systemic inflammation. The presence of systemic inflammation-induced tissue resistance to glucocorticoids and/or inadequate adrenal output might explain why older clinical trials found no efficacy with a time-limited course of massive doses of glucocorticoids $[14,15]$. On the other hand, other studies have shown that prolonged treatment with moderate doses of corticosteroids might improve intracellular down-regulation of inflammatory cytokine transcription and hasten the resolution of the illness $[16,17]$.

In a multicentre study conducted on CAP patients admitted to the ICU and received antibiotic treatment. The patients were randomly assigned to receive either hydrocortisone or placebo for 7 days. Treated patients showed a significant improvement in $\mathrm{PaO}_{2}: \mathrm{FIO}_{2}$ and chest radiograph score. Also, a significant reduction in C-reactive protein (CRP) levels, MODS score, and delayed septic shock were observed, with a significant decline in the periods the patients spent in hospital and mortality [18].

Salluh and co-authors investigated four studies focused on the use of corticosteroid in the management of CAP [5]. They showed that, the administration of corticosteroids demonstrated an improvement in both the physiological and clinical status without evidence for any increased harm.

This issue is not new, as the use of steroids as an adjunct therapy in the management of pneumonia has been recommended for more than 60 years [19]. The encouraging results of the recent low-dose hydrocortisone trials together with the fact that, till the time of writing this manuscript, glucocorticoids are not regularly used as a treatment of pneumonia in the ICUs in the Egyptian hospitals, generated the aim of the present study and evoked a reassessment of the role of glucocorticoids in CAP in the Egyptian ICUs.

\section{Aim}

The aim of the study was to assess the efficacy and safety of adjunctive low dose hydrocortisone infusion treatment in Egyptian ICU patients with CAP.

\section{Methodology}

\subsection{Patients and Settings}

This study was conducted between July 2010 and January 2011 where eighty adult subjects were enrolled in a randomized, double blind, interventional study. The study was conducted at critical care department, $3^{\text {rd }}$ unit, Cairo University, and the National Institute of Chest Diseases, and Intensive Care Unit of Ain-Shams Hospital, AinShams University.

Each institutional review board approved the study protocol, and the protocol of the study was registered in
ClinicalTrials.gov (ref. number: NCT01228110).

Patients to be eligible for this study should be meeting the following criteria (1) presence of CAP, including two minor or one major 1998 American Thoracic Society (ATS) criterion for severe pneumonia which is modified in 2007 [20].

Minor criteria included [18]

- Respiratory rate $>30 \mathrm{bpm}$ on admission;

- Ratio of $\mathrm{PaO}_{2}$ to fraction of inspired oxygen $\left(\mathrm{PaO}_{2}: \mathrm{FIO}_{2}\right)<250$;

- Chest radiograph showing bilateral involvement or multilobar involvement;

- Systolic blood pressure < $90 \mathrm{~mm} \mathrm{Hg}$; or diastolic blood pressure $<60 \mathrm{~mm} \mathrm{Hg}$.

Major criteria included [18]

- Requirement of MV;

- Increase in the size of opacities on chest radiograph of $\geq 50 \%$ at 48 hours;

- Requirement of vasopressors $>4$ hours; or

- Serum creatinine $\geq 2 \mathrm{mg} / \mathrm{dl}$ or more.

Exclusion criteria:

- Children

- Aspiration or hospital acquired pneumonia;

- Discharge from hospital within the previous 14 days;

- Transferred from another hospital;

- Immunosuppressed patients;

- Chronic chest disease; TB, obstructive pneumonia; cystic fibrosis, bronchiectasis;

- Concomitant infections (e.g., sinusitis, urinary tract infections);

- Congestive heart failure (CHF);

- Chronic renal or hepatic disease;

- Acute burn injury;

- Malignancy;

- Pregnancy; and

- Major gastrointestinal bleed within 3 months of the current hospitalization.

\subsection{Study Design}

Intervention group patients received maximal conventional therapy plus intravenous hydrocortisone (loading dose of $200 \mathrm{mg}$ over 30 minutes, followed by $300 \mathrm{mg}$ in $500 \mathrm{ml} 0.9 \%$ saline at a rate of $12.5 \mathrm{mg} / \mathrm{hr}$ ) for 7 days. The Control group subjects were entitled to receive the maximal conventional therapy plus equal volume of intravenous normal saline solution as placebo.

Patients continued to receive standard treatment after Day 7, and in the incidences of hemodynamic instabilities, hydrocortisone was administered according to the physicians' clinical judges.

The following variables were recorded:

1) demographic data (age, sex, DOB); 
2) comorbidities;

3) routine laboratory screen and arterial blood gas (ABG) at least once daily;

4) cause of pneumonia;

5) administered antibiotic regimen;

6) chest X-ray at least on admission and at day 8; and

7) Sepsis-related Organ Failure Assessment (SOFA) score daily

8) days from diagnosis to death.

The primary outcomes were improvement in $\mathrm{PaO}_{2}: \mathrm{FIO}_{2}$ $\left(\mathrm{PaO}_{2}: \mathrm{FIO}_{2}>300\right.$ or $\geq 100$ increase from study entry), SOFA score by day 8 and the development of delayed septic shock. The adopted SOFA score was proposed by Vincent et al. [21].

The number of MV-free days was defined as "the number of days after ventilation was discontinued" up to study day 8. Shock was defined as "requirement of vasopressors". ARDS was defined by consensus criteria [22].

\subsection{Statistical Analysis}

Patients who were placed on systemic steroid therapy concomitant were compared with those not receiving steroids. Descriptive statistics were generated, specifically means, standard deviations and ranges. To minimize type I error, a $p$ value equal to or less than 0.05 was taken as cut-off level for the level of significance. The main tests being used to analyze data extracted from this study are the Mann-Whitney for nominal continuous data.

Wilcoxon signed rank test was also used to compare the observed mean difference of the data arising when the same individuals are studied more than once. The chi-squared $\left(\mathrm{X}^{2}\right)$ test for categorical data used to identify by how much the two observations differ and also whether this difference is more than might reasonably be expected to occur in sampling. Statistical Package for Social Science (SPSS) was used for data analysis.

\section{Results}

In total, 80 patients hospitalized with severe CAP were recruited to be allocated to one of the two previously described groups. Of these 80 subjects, $72.25 \%$ were male with a mean (range) age of $62.23(50$ - 72) years.

At baseline, the 2 groups were comparable regarding the general characteristics including age, sex, initial body temperature, blood pressure, the diagnosis of underlying diseases, severity of illness, MV and vasopressors requirements, and microbiological results. The two groups were also comparable regarding the respiratory rate $>30$ bpm, $\mathrm{PaO}_{2}: \mathrm{FIO}_{2}<200$, chest X-ray assessment, and other parameters at the beginning of the study (Table 1).

$\mathrm{S}$. pneumoniae was the most common offending microorganism, followed by L. pneumophila, but the causative pathogen could not be identified in many of the patients as the culture specimen was sampled post antibiotics initiation. Almost all patients were initially treated empirically with intravenous antibiotic agents.

When the two study groups were compared, a significant elevation in $\mathrm{PaO}_{2}: \mathrm{FIO}_{2}$ was recorded within the hydrocortisone group by the first day, and within the placebo group by the $4^{\text {th }}$ day $(\mathrm{p}=0.027$ and 0.01 respectively). By day 8 , a $\mathrm{PaO}_{2}: \mathrm{FIO}_{2} \geq 300$ was observed in $10(25 \%)$ placebo group patients versus $28(70 \%)$ patients in the steroid group with a level of significance of $\mathrm{p}=0.003 . \mathrm{PaO}_{2}: \mathrm{FIO}_{2}$ improved by $\geq 100$ from study entry was observed in 36 $(90 \%)$ of the study group compared to $12(30 \%)$ patients in the placebo group $(\mathrm{p}<0.001)$ (Table 2).

Table 1. Subject baseline characteristics in the two main groups.

\begin{tabular}{|c|c|c|c|}
\hline Parameter & Placebo $(\mathrm{N}=40)$ & Hydrocortisone $(\mathrm{N}=40)$ & $\mathrm{p}^{*}$ \\
\hline Male Distribution (\%) & $28(70)$ & $30(75)$ & $0.723 * *$ \\
\hline Average Age in years $(\mathrm{SD})^{\dagger}$ & $62.5(4.26)$ & $61.95(6.97)$ & $0.850^{\ddagger}$ \\
\hline Age range in years & $55-70$ & $50-72$ & \\
\hline Average SOFA score (SD) & $8.2(1.46)$ & $8.5(1.52)$ & $0.75^{\ddagger}$ \\
\hline Average Body Temperature, ${ }^{\circ} \mathrm{C}(\mathrm{SD})$ & $38.210(0.43)$ & $37.910(0.61)$ & $0.114^{\ddagger}$ \\
\hline Average WBC count $x$ 109/L (SD) & $16.5(4.11)$ & $17.1(3.97)$ & $0.232^{\ddagger}$ \\
\hline Number of patients on MV (\%) & $34(85 \%)$ & $26(65 \%)$ & $0.144 * *$ \\
\hline Average $\mathrm{PaO}_{2}: \mathrm{FIO}_{2}(\mathrm{SD})$ & $182(52)$ & $178(48)$ & $0.061^{\ddagger}$ \\
\hline Number of patients with $\mathrm{PaO}_{2}: \mathrm{FIO}_{2}<200(\%)$ & $28(70)$ & $32(80)$ & $0.465 * *$ \\
\hline $\begin{array}{l}\text { Number of patients with catecholamine-dependent } \\
\text { septic shock }(\%)\end{array}$ & $4(10)$ & $8(20)$ & $0.376^{* *}$ \\
\hline Average CRP (mg/dl) & $58.7(10.44)$ & $55(15.38)$ & $0.438^{\star}$ \\
\hline Average Chest radiograph score (SD) & $2.5(0.58)$ & $2.8(0.71)$ & $0.0 .712^{4}$ \\
\hline
\end{tabular}

$* p$ is the level of significance. $* *$ Chi-square test was used to compare the groups at level of significance of $<0.05$. ${ }^{\dagger}$ SD: Standard Deviation. ${ }^{\ddagger}$ Mann Whitney test was used to compare the groups at level of significance of $<0.05$. 
Table 2. Clinical and physiological characteristics by study day 8.

\begin{tabular}{|c|c|c|c|}
\hline Parameter & Placebo $(\mathrm{N}=40)$ & Hydrocortisone $(\mathrm{N}=40)$ & $\mathbf{p}^{*}$ \\
\hline Mean SOFA score (SD) & $3.0(0.90)$ & $1.1(0.53)$ & $0.003^{\ddagger}$ \\
\hline Number of patients on mechanical ventilation (\%) & $26(65 \%)$ & $10(25 \%)$ & $0.011^{* *}$ \\
\hline Mean time from weaning of ventilated patients up to day 8 (SD) & $1.2(0.42)$ & $3.4(0.58)$ & $0.01^{\ddagger}$ \\
\hline Mean $\mathrm{PaO}_{2}: \mathrm{FIO}_{2}(\mathrm{SD})$ & $243(45)$ & $338(39)$ & $0.0008^{\ddagger}$ \\
\hline Number of patients with $\mathrm{PaO}_{2}: \mathrm{FIO}_{2} \geq 300(\%)$ & $10(25)$ & $28(70)$ & $0.004^{* *}$ \\
\hline $\begin{array}{l}\text { Number of patients with } \mathrm{PaO}_{2}: \mathrm{FIO}_{2} \text { improvement } \geq 100 \text { from study } \\
\text { entry }(\%)\end{array}$ & $12(30)$ & $36(90)$ & $0.000^{* *}$ \\
\hline Mean Chest radiograph score (SD) & $2.7(1.34)$ & $1.3(0.63)$ & $0.0001^{\ddagger}$ \\
\hline $\begin{array}{l}\text { Number of patients with improvement in chest radiograph score } \\
\text { from Day } 1 \text { to } 8(\%)\end{array}$ & $10(25)$ & $36(90)$ & $0.000^{* *}$ \\
\hline Number of patients with MODS (\%) & $26(65)$ & $12(30)$ & $0.027^{* *}$ \\
\hline Number of patients with Delayed septic shock (\%) & $14(35)$ & $2(5)$ & $0.018^{* *}$ \\
\hline Number of patients with New ARDS (\%) & $6(15 \%)$ & $2(5 \%)$ & $0.292^{* *}$ \\
\hline Mean CRP (mg/dl) (range) & $36(3-231)$ & $17(2-49)$ & $0.0001^{\ddagger}$ \\
\hline Number of Survival by day 8 (\%) & $34(85 \%)$ & $38(95 \%)$ & $0.633^{* *}$ \\
\hline
\end{tabular}

$* \mathrm{p}$ is the level of significance. ${ }^{\ddagger}$ Mann Whitney test was used to compare the groups at level of significance of $<0.05$. ** Chi-square test was used to compare the groups at level of significance of $<0.05$.

At study day 1, 34 versus 26 patients in placebo and hydrocortisone groups respectively were placed on MV $(\mathrm{p}=0.18)$, while at day 8,26 versus 10 patients in placebo and hydrocortisone groups respectively were still ventilated $(\mathrm{p}=0.01)$. Also, the hydrocortisone group showed a significant reduction $(\mathrm{p}=0.002)$ in the duration of MV by day 8 (Figure $\mathbf{1}$ ).

A progressive reduction in CRP values was observed in the hydrocortisone group. A significant difference $(\mathrm{p}=$ 0.0001 ) from the control group was reported by day 8 (Figure 2).

When the two groups were compared with respect to the major complications experienced by the recruited patients, it was found that $6(15 \%)$ placebo patients developed ARDS, $2(5 \%)$ died by day 5; the other $4(10 \%)$ died by day 7. Survival to ICU discharge was $85 \%$ in the placebo

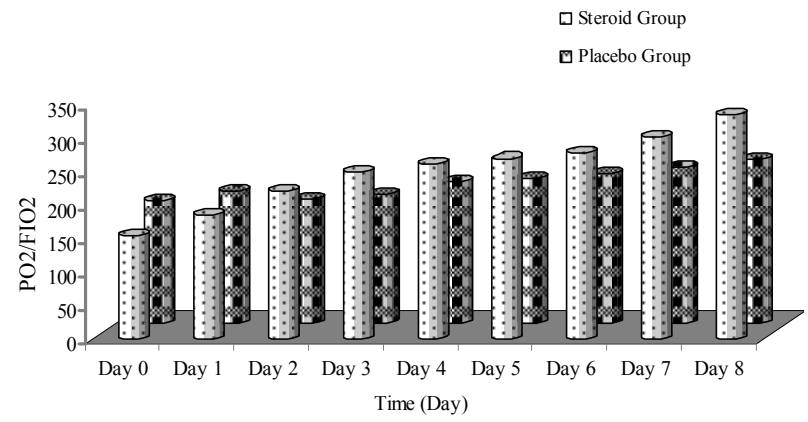

Figure 1. $\mathrm{PaO}_{2} / \mathrm{FIO}_{2}$ ratio curve during the study. group and $95 \%$ in the hydrocortisone group with no significant difference between the two groups $(\mathrm{p}=0.66)$. All non-survivors required $\mathrm{MV}$ and had progression of radiographic densities on chest radiograph. All (95\%) but 2 patients developed pressor-dependent shock. The 2 patients without shock had L. pneumonia that progressed to ARDS. Other complications included two (5\%) liver failure cases, and two (5\%) lung abscess cases in the placebo group, and two (5\%) drug-induced hepatitis conditions in the hydrocortisone-treated group (Figure 3).

Adverse events were few and the two groups were comparable.

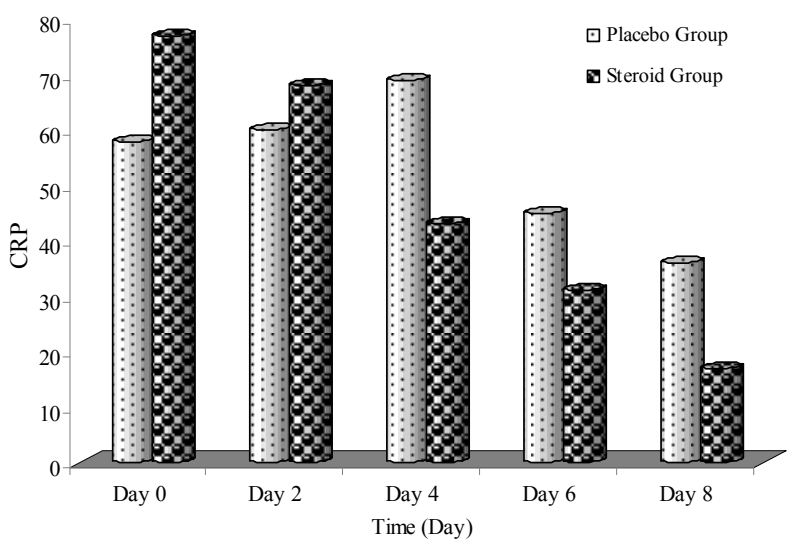

Figure 2. CRP values during the study. 


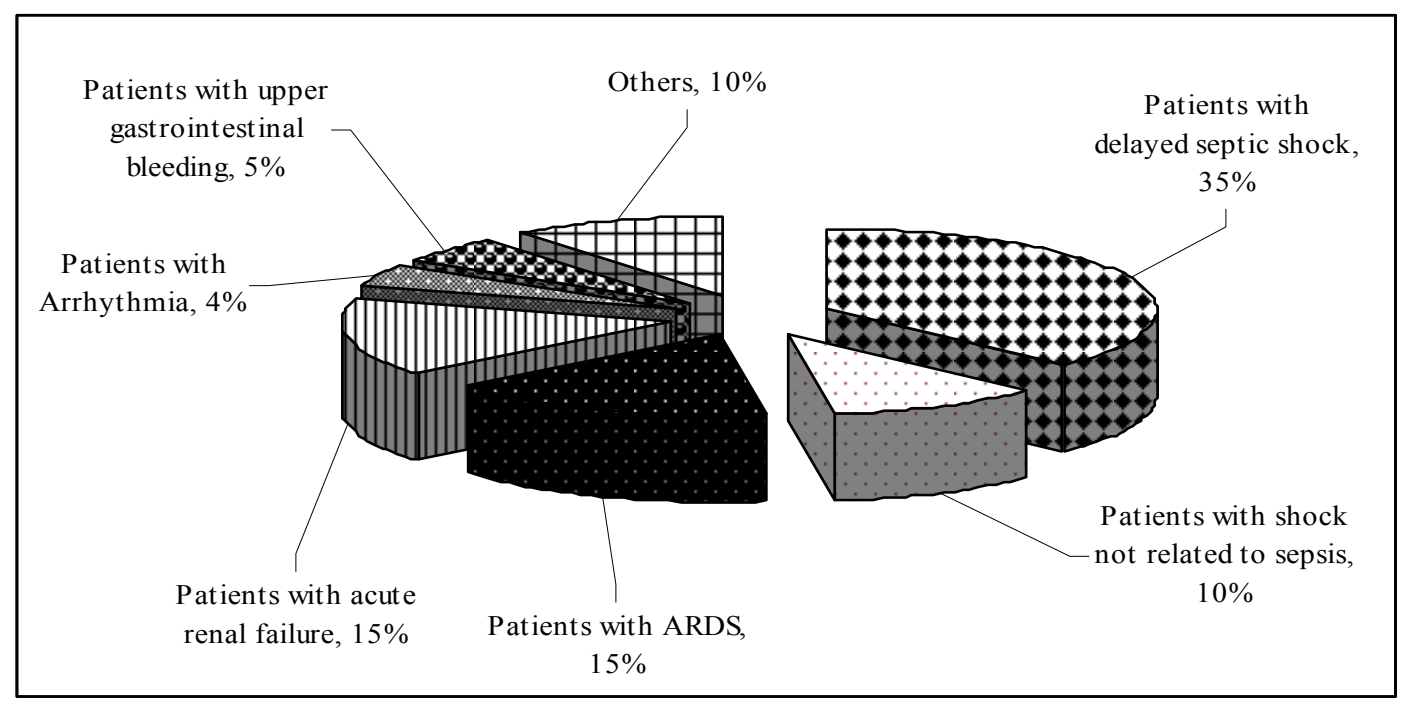

(a)

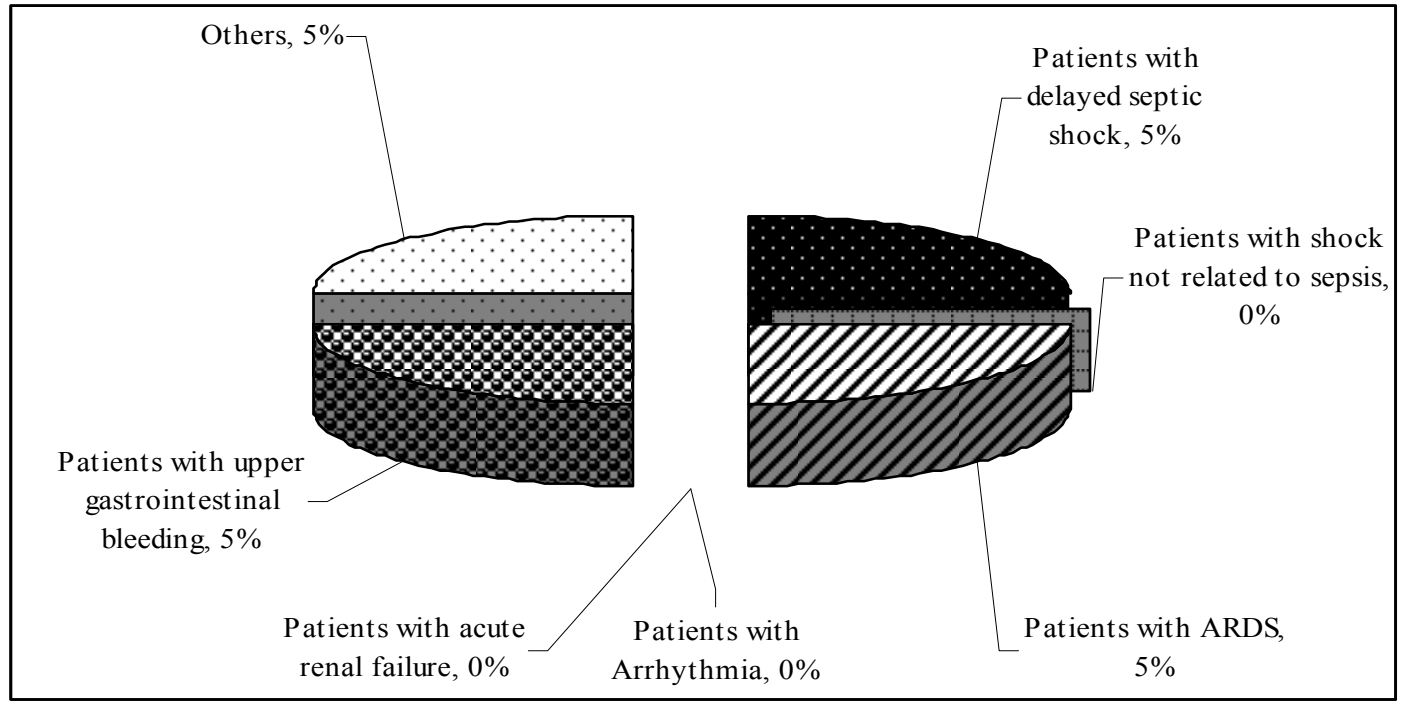

(b)

Figure 3. Complication during the Study, where (A) represents the complications in the placebo group, while (B) represents the complications in the hydrocortisone group.

\section{Discussion}

Corticosteroids have been used successfully in the management of several infective and non-infective respiratory conditions, including miliary TB, [23] Pneumocystis carinii pneumonia, [24] AIDS and other immunocompromised states, vasculitides [25] gastric acid aspiration, [26] and ARDS [27]. Other studies have demonstrated the efficacy of steroid in managing septic shock, [28] meningitis, [29] and pneumonia caused by Pneumocystis jiroveci [30].

Although this is not the first study evaluating the effi- cacy and safety of hydrocortisone in patients with pneumonia, it is the first one to focus on management of CAP in the Egyptian ICUs.

In the present study, hydrocortisone treated patients showed a significant improvement in $\mathrm{PaO}_{2}: \mathrm{FIO}_{2}$, chest radiograph score, and a significant decline in SOFA score, CRP levels, and delayed septic shock when compared to the control group. Hydrocortisone treatment was associated with a significant decline in the duration of MV. However, hydrocortisone infusion did not show significant difference in the ICU mortality.

It is expected that systemic inflammation can occur in 
patients with severe CAP. Several studies have reported increased local and systemic inflammatory cytokine levels in CAP patients as the first step of the immune response. These studies recommended the presence of a fine balance between cytokine pro-inflammatory and anti-inflammatory activities, which is very critical in the host response [6,7,31]. Sibila et al. explained in a study conducted on severe pneumonia patients, that despite the inflammatory response initially being compartmentalised, elevation in plasma cytokine levels is detected and was strongly connected to poor prognosis [32].

Yende et al. in 2005, has demonstrated that patients with increased levels of inflammatory cytokines prior to infection were at higher risk of suffering from CAP. This could be attributed to the up-regulated adherence of bacteria to human alveolar epithelial cells. This happens by increasing expression of receptors that bind to these organisms suggesting an essential role of the inflammatory response in the pathogenicity of the infection [33].

Evidence recommends that early administration of corticosteroids may modify the inflammatory response [34]. It is believed that corticoids inhibit the action of many cytokines associated with pneumonia. At the molecular level, corticosteroids inhibits the transcription of genes coding for cytokines, results in a decrease in the release of macrophage-derived pro-inflammatory cytokines [35], which in turn inhibits the T-cells and eosinophil functions. Production of leukotrienes and prostaglandins is also inhibited [36]. It is also possible that corticosteroids may favorably alter pulmonary heamodynamics [37].

The response to hydrocortisone treatment observed in the present study and in other randomized trials of patients with septic shock [28,38-41] and severe pneumocystis pneumonia [42] contrasts with the negative findings of older trials. These negative finding may be related to the short duration of treatment $[14,15]$. Among a number of studies in support of this hypothesis [14], a randomized trial of patients with severe CAP found that a single dose of hydrocortisone $(10 \mathrm{mg} / \mathrm{kg})$ before antibiotic administration showed no effect on plasma TNFlevels [43].

On the other hand, Monton and coworkers [44] demonstrated that the co-administration of steroids with antibiotic treatment reduces the lung inflammatory responses in severe pneumonia and on MV, which supports the results of the present study.

In 2006, Mikami et al. studied the effect of low dose steroids on Japanese adult CAP patients, who received 40 $\mathrm{mg}$ intravenous prednisolone for 7 days. The steroids group demonstrated faster stabilization, which lead to the conclusion that, the administration of corticosteroids in moderate-severe CAP, resolve the clinical symptoms and shorten the duration of intravenous antibiotic therapy [45].

The same dose of prednisolone was used for the same duration in a study conducted by Snijders et al., in 2010 and opposing to what was expected, the results were different. Although patients on prednisolone had faster defervescence and faster decline in serum CRP levels compared with placebo, data analysis did not show differences in clinical outcome. Late failure was significantly more common in the patients who had prednisolone than those on placebo. So, it was concluded that $40 \mathrm{mg}$ prednisolone daily for one week does not improve the outcomes in hospitalized patients diagnosed with CAP [46].

Keh et al. [28] confirmed the beneficial effects of low-dose glucocorticoids, where rapid haemodynamic stabilization was achieved in patients with septic shock who received low doses of hydrocortisone. They confirmed that hydrocortisone attenuates the inflammatory response, but does not have any effect on macrophages and monocytes.

The correlation between organ failure, assessed by MODS, and systemic inflammation, assessed by CRP, suggests that a good clinical course is associated with resolution of the inflammatory process whereas a clinical deterioration is associated with ongoing inflammation. The justification of the clinical improvement shown in the present study can be based on what was explained by Confalonieri et al., which was based on possible immunomodulatory effects of the steroid infusion, thus accelerating the development of acute lung injury and multiorgan failure [18].

It was also observed in the present study that, no evidence for any increased risk of superinfection, bleeding, or neuromuscular weakness, whereas hypernatremia and hyperglycaemia occurred more frequently in the studied subjects. Sprung et al., showed an increased incidence of superinfection, including new episodes of sepsis or septic shock, in the hydrocortisone group [47]. This variation in the results may be attributed to the variation in the doses used and the duration of the treatment, where in Sprung et al. study, hydrocortisone was used for the longer treatment period. Previous studies with high-dose corticosteroids have shown similar findings to the present study, whereas the study conducted by the Acute Respiratory Distress Syndrome (ARDS) Network [48] using higher doses of corticosteroids and meta-analyses of studies that used low doses $[15,49]$ did not report higher rates of infectious complications.

Despite these results, it is still important for physicians to adopt prophylactic measures and to screen the patients daily for possible complications.

Studies involving critically ill patients have reported an association between corticosteroid therapy and the incidence of neuromuscular weakness $[48,50]$. We did 
not see this in the present study, although electrophysiological testing was not performed.

Regarding the mortality, in contrast to what was found in the present study, two studies found a significant reduction in mortality for patients with severe CAP treated with corticosteroids $[9,18]$. Garcia-Vidal and colleagues [9] evaluated 308 patients in a large retrospective single-center cohort study and demonstrated that the use of corticosteroids was strongly associated with a lower mortality. The discrepancies between the two studies may be attributed to the difference in the type of the study and the adopted type of corticosteroid and the treatment duration period, were these patients were treated with a median dose of $45 \mathrm{mg} /$ day of methylprednisolone for a mean period of 11.4 days.

The study of Confalonieri and colleagues [18], showed an impressive reduction in hospital mortality with a 7 -day continuous infusion of hydrocortisone (240 mg/day). This difference may be attributed to the difference in the sample size used in the present study ( 80 patients) and in Confalonieri study (46 patients).

Based upon the clinical observations, it is believed that low dose of corticosteroid should be considered in addition to the antibacterial therapy together with an appropriate supportive care in the management of pneumonia. This study should form the nucleus for other randomized studies in Egypt as no other relevant studies are available nationally.

\section{Study Limitation}

The small sample size was the main weak point in present study. This can be attributed to the self-funding nature of the study. This limited sample size may have biased the estimate of the treatment effect on mortality, a larger randomized trial is recommended to support the mortality findings of this trial.

Secondly, old weaning guidelines were used and NIV was not adopted in the two studied centers. However, because of the parallel control nature of the study, the two designed groups were treated in the same way, where any difference in the outcomes between the two studied groups could be attributed to the corticosteroid intervention.

Finally, in developing countries, due to limited access to expensive diagnostic procedures, it was difficult to assess the adrenal gland functions and the endogenous steroids.

\section{Conclusion}

Among the hospitalized patients with CAP, hydrocortisone was associated with significant clinical improvement, fastens recovery of pneumonia and prevented the development of sepsis related complications with a significant reduction in MV duration, but it does not affect the mortality. At least for now, corticosteroids should routinely be used as adjunctive therapy for CAP in the ICU.

\section{Acknowledgements}

This was a self-funded study. The authors would like to acknowledge the great efforts made by the staff of the ICUs in the study hospitals. Special thanks for Dr. Manal El-Attar for her great help.

\section{REFERENCES}

[1] M. Woodhead, "Community-Acquired Pneumonia," In: J. Franklin, Ed., Horizons in Medicine, Royal College of Physicians, London, 2004, pp. 165-173.

[2] "Statistical Abstract of the United States," 104th Edition, Washington DC, US Government Printing Office, 1984.

[3] S. H. Feinsilver, A. M. Fein, M. S. Niederman, D. E. Schultz and D. H. Faegenburg "Utility of Fiberoptic Bronchoscopy in Nonresolving Pneumonia," Chest, Vol. 98, No. 6, 1990, pp. 1322-1326. doi:10.1378/chest.98.6.1322

[4] M. S. Niederman, L. A. Mandell, A. Anzueto, J. B. Bass, W. A. Broughton, G. D. Campbell, N. Dean, T. File, M. J. Fine, P. A. Gross, F. Martinez, T. J. Marrie, J. F. Plouffe, J. Ramirez, G. A. Sarosi, A. Torres, R. Wilson and V. L. $\mathrm{Yu}$, "Guide Lines for the Management of Adults with Community-Acquired Pneumonia. Diagnosis, Assessment of Severity, Antimicrobial Therapy, and Prevention," American Journal of Respiratory and Critical Care Medicine, Vol. 163, No. 7, 2001, pp. 1730-1754.

[5] J. Salluh, P. Póvoa, M. Soares, H. Castro-Faria-Neto, F. Bozza and P. Bozza, "The Role of Corticosteroids in Severe Community-Acquired Pneumonia: A Systematic Review," Critical Care, Vol. 12, No. 3, 2008, pp. 76-82. doi:10.1186/cc6922

[6] C. Monton, A. Torres, M. El-Ebiary, X. Filella, A. Xaubet and J. P. De la Bellacasa, "Cytokine Expression in Severe Pneumonia: A Bronchoalveolar Lavage Study," Critical Care Medicine, Vol. 27, No. 9, 1999, pp. 17451753. doi:10.1097/00003246-199909000-00008

[7] S. Fernandez-Serrano, J. Dorca, M. Coromines, J. Carratala, F. Gudiol and F. Manresa, "Molecular Inflammatory Responses Measured in Blood of Patients with Severe Community-Acquired Pneumonia," Clinical and Diagnostic Laboratory Immunology, Vol. 10, No. 5, 2003, pp. 813-820.

[8] G. Antunes, S. A. Evans, J. L. Lordan and A. J. Frew, "Systemic Cytokine Levels in Community-Acquired Pneumonia and Their Association with Disease Severity," European Respiratory Journal, Vol. 20, No. 4, 2002, pp. 990-995. doi:10.1183/09031936.02.00295102

[9] C. Garcia-Vidal, E. Calbo, V. Pascual, C. Ferrer, S. Quintana and J. Garau, "Effects of Systemic Steroids in Patients with Severe Community-Acquired Pneumonia," European Respiratory Journal, Vol. 30, No. 5, 2007, pp. 


\section{1-956. doi:10.1183/09031936.00027607}

[10] H. Schutte, J. Lohmeyer, S. Rosseau, S. Ziegler, C. Siebert, H. Kielisch, H. Pralle, F. Grimminger, H. Morr, and W. Seeger, "Bronchoalveolar and Systemic Cytokine Profiles in Patients with ARDS, Severe Pneumonia and Cardiogenic Pulmonary Oedema," European Respiratory Journal, Vol. 9, No. 9, 1996, pp. 1858-1867. doi:10.1183/09031936.96.09091858

[11] R. Mene'ndez, A. Torres, R. Zalacain, J. Aspa, J. J. Martin Villasclaras, L. Borderias, J. M. Benitez Moya, J. Ruiz-Manzano, F. Rodriguez de Castro, J. Blanquer, D. Perez, C. Puzo, F. Sanchez Gascon, J. Gallardo, C Alvarez and L. Molino, "Predictive Factors of Clinical Stability in Community-Acquired Pneumonia," Thorax, Vol. 59, 2004, pp. 960-965.

[12] M. Ioanas, M. Ferrer, M. Cavalcanti, .R Ferrer, S. Ewig, X. Filella, J. P. dela Bellacasa and A. Torres, "Causes and Predictors of Nonresponse to Treatment of ICU-Acquired Pneumonia," Critical Care Medicine, Vol. 32, No. 4, 2004, pp. 938-945. doi:10.1097/01.CCM.0000114580.98396.91

[13] G. P. Chrouso, "Stressors, Stress, and Neuroendocrine Integration of the Adaptive Response," The 1997 Hans Selye Memorial Lecture, Annals New York Academy of Sciences, Vol. 851, 1998, pp. 311-335. doi:10.1111/j.1749-6632.1998.tb09006.x

[14] G. U. Meduri, "An Historical Review of Glucocorticoid Treatment in Sepsis. Disease Pathophysiology and the Design of Treatment Investigation," Sepsis, Vol. 3, 1999, pp. 21-38. doi:10.1023/A:1009870524359

[15] P. C. Minneci, K. J. Deans, S. M. Banks, P. Q. Eichacker, and C. Natanson, "Meta-Analysis: The Effect of Steroids on Survival and Shock during Sepsis Depends on the Dose," Annals of International Medicine, Vol. 141, No. 1, 2004, pp. 47-56.

[16] P. E. Marik, S. M. Pastores, D. Annane, G. U. Meduri, W. Arlt, C. L. Sprung, D. Keh, J. Briegel, A. Beishuizen, I. Dimopoulou, S. Tsagarakis, M. Singer, G. P. Chrousos, G. Zaloga, F. Bokhari and M. Vogeser, "Clinical Practice Guidelines for the Diagnosis and Management of Corticosteroid Insufficiency in Critical Illness: Recommendations of an International Task Force," Critical Care Medicine, Vol. 36, No. 6, 2008, pp. 1937-1949. doi:10.1097/CCM.0b013e31817603ba

[17] M. Mer, and G. A. Richards, "Pneumonia Corticosteroids in Life-Threatening Varicella," Chest, Vol. 114, No. 2, 1998, pp. 426-431. doi:10.1378/chest.114.2.426

[18] M. Confalonieri, R. Urbino, A. Potena, M. Piattella, P. Parigi, G. Puccio, R. Della Porta, C. Giorgio, F. Blasi, R. Umberger and G. U. Meduri, "Hydrocortisone Infusion for Severe Community-Acquired Pneumonia: A Preliminary Randomized Study," American Journal of Respiratory and Critical Care Medicine, Vol. 171, No. 3, 2005, pp. 242-248.

[19] D. Perla and J. Marmorston, "Suprarenal Cortical Hormone and Salt in the Treatment of Pneumonia and Other Severe Infections," Endocrinology, Vol. 27, No. 3, 1940, pp. 367-374. doi:10.1210/endo-27-3-367
[20] S. Ewig, M. Ruiz, J. Mensa, M. A. Marcos, J. A. Martinez, F. Arancibia, M. S. Niederman and A. Torres, "Severe Community-Acquired Pneumonia: Assessment of Severity Criteria," American Journal of Respiratory and Critical Care Medicine, Vol. 158, No. 4, 1998, pp. 1102 -1108 .

[21] J. L. Vincent, R. Moreno, J. Takala, S. Willatts, A. De Mendonça, H. Bruining, C. K. Reinhart, P. M. Suter, and L. G. Thijs. "The SOFA (Sepsis-Related Organ Failure Assessment) Score to Describe Organ Dysfunction/Failure," Intensive Care Medicine, Vol. 22, No. 7, 1996, pp. 707-710. doi:10.1007/BF01709751

[22] G. R. Bernard, A. Artigas, K. L. Brigham, J. Carlet, K. Falke, L. Hudson, M. Lamy, J. R. LeGall, A. Morris and R. Spragg, "The American-European Consensus Conference on ARDS: Definitions, Mechanisms, Relevant Outcomes, and Clinical Trial Coordination," American Journal of Respiratory and Critical Care Medicine, Vol. 149, No. 3, 1994, pp. 818-24.

[23] T. Senderovitz and K. Viskun, "Corticosteroids in Tuberculosis," Respiratory Medicine, Vol. 88, 1994, pp. 561-565. doi:10.1016/S0954-6111(05)80002-2

[24] S. A. Bozette, F. R. Sattler and J. Chiu, "A Controlled Trial of Early Adjunctive Treatment with Corticosteroids for Pneumocystis Carinii Pneumonia in the Acquired Immunodeficiency Syndrome," New England Journal of Medicine, Vol. 323, No. 21, 1990, pp. 1451-1457. doi:10.1056/NEJM199011223232104

[25] R. H. Leavitt and A. S. Fauci, "Pulmonary Vasculitis," American Review of Respiratory Diseases, Vol. 134, No. 1, 1986, pp. 149-166

[26] W. K. Bannister, A. J. Sattilano and R. D. Otis, "Therapeutic Aspects of Aspiration Pneumonitis in Experimental Animals," Anesthiology, Vol. 23, 1961, pp. 440-445. doi:10.1097/00000542-196105000-00017

[27] C. U. Meduri, S. Headley, S. Carson, et al. "Methylprednisolone Treatment of Late ARDS," American Journal of Respiratory and Critical Care Medicine, Vol. 155, 1997, p. A391.

[28] D. Keh, T. Boehnke, S. Weber-Cartens, C. Schulz, O. Ahlers, S. Bercker, H. Volk, W. Doecke, K. J. Falke and H. Gerlach, "Immunologic and Hemodynamic Effects of 'Low-Dose' Hydrocortisone in Septic Shock. A Double Blind, Randomized, Placebo-Controlled, Crossover Study," American Journal of Respiratory and Critical Care Medicine, Vol. 167, No. 4, 2003, pp. 512-520. doi:10.1164/rccm.200205-446OC

[29] L. A. Mandell, R. G. Wunderink, A Anzueto, J. G. Bartlett, G. D. Campbell, A. Torres and C. G. Whitney, "Guidelines for the Initial Management of Adults with Community-Acquired Pneumonia: Diagnosis, Assessment of Severity, and Initial Antimicrobial Therapy. American Thoracic Society. Medical Section of the American Lung Association," American Review of Respiratory Diseases, Vol. 148, No. 5, 2007, pp. 1418-1426.

[30] M. Briel, R. Boscacci, H. Furrer and H. C. Bucher, "Adjunctive Corticosteroids for Pneumocystis Jiroveci Pneumonia in Patients with HIV infection: A Meta-Analysis of 
Randomized Controlled Trials," BMC Infectious Diseases, Vol. 5, 2005, p. 101. doi:10.1186/1471-2334-5-101

[31] J. Puren, C. Feldman, N. Savage, P. J. Becker and C. Smith, "Patterns of Cytokine Expression in CommunityAcquired Pneumonia," Chest, Vol. 107, No. 5, 1995, pp. 1342-1349. doi:10.1378/chest.107.5.1342

[32] Sibila, C. Agusti and A. Torres, "Corticosteroids in Severe Pneumonia," European Respiratory Journal, Vol. 32, No. 2, 2008, pp. 259-264. doi:10.1183/09031936.00154107

[33] S. Yende, E. I. Tuomanen, R. Wunderink, A. Kanaya, A. B. Newman, T. Harris, N. De Rekeneire and S. B. Kritchevsky, "Preinfection Systemic Inflammatory Markers and Risk of Hospitalization Due to Pneumonia," American Journal of Respiratory and Critical Care Medicine, Vol. 172, No. 11, 2005, pp. 1440-1446. doi:10.1164/rccm.200506-8880C

[34] C. U. Meduri, "The Role of the Host Defense Response in the Progression and Outcome of ARDS: Pathophysiological Correlations and Response to Gluococorticoid Treatment," European Respiratory Journal, Vol. 9, No. 12, 1996, pp. 2650-2670. doi:10.1183/09031936.96.09122650

[35] P. J. Barnes and I. Adcock, "Anti-Inflammatory Actions of Steroids: Molecular Mechanisms," Trends in Pharmacological Sciences, Vol. 14, No. 12, 1993, pp. 436-441. doi:10.1016/0165-6147(93)90184-L

[36] S. Hong and L. Levine, "Inhibition of Arachidonic Acid Release from Cells as the Biochemical Actions of Anti-Inflammatory Steroids," Proceedings of the National Academy of Sciences USA, Vol. 73, No. 5, 1976, pp. 1730-1733. doi:10.1073/pnas.73.5.1730

[37] T. J. K. Toung, D. Bordos, D. W. Benson, D. Carter, G. D. Zuidema, S. Permutt and L. Cameron, "Aspiration Pneumonia: Experimental Evaluation of Albumin and Steroid Therapy," Annals of Surgery, Vol. 183, No. 2, 1976, pp. 179-184. doi:10.1097/00000658-197602000-00016

[38] P. E. Bollaert, C. Charpentier, B. Levy, M. Debouverie, G. Audibert and A. Larcan, "Reversal of Late Septic Shock with Supraphysiologic Doses of Hydrocortisone," Critical Care Medicine, Vol. 26, No. 4, 1998, pp. 645-650. doi:10.1097/00003246-199804000-00010

[39] K. Chawla, Y. Kupfer, I. Goldman and S. Tessler, "Hydrocortisone Reverses Refractory Septic Shock," Critical Care Medicine, Vol. 27, No. 1, 1999, p. A33. doi:10.1097/00003246-199901001-00022

[40] Yildiz, M. Doganay, B. Aygen, M. Guven, F. Keleutimur and A. Tutuu, "Physiological-Dose Steroid Therapy in Sepsis," Critical Care, Vol. 6, No. 3, 2002, pp. 251-259. doi:10.1186/cc1498

[41] D. Annane, V. Sebille, C. Charpentier, P. E. Bollaert, B. Francois, J. M. Korach, G. Capellier, Y. Cohen, E. Azoulay, G. Troche, et al., "Effect of Treatment with Low Doses of Hydrocortisone and fludrocortisone on Mortality in Patients with Septic Shock," Journal of the American Medical Association, Vol. 288, No. 7, 2002, pp. 862-871. doi:10.1001/jama.288.7.862

[42] M. A. Jantz and S. A. Sahn, "Corticosteroids in Acute Respiratory Failure," American Journal of Respiratory and Critical Care Medicine, Vol. 160, No. 4, 1999, pp. 1079-1100.

[43] P. Marik, P. Kraus, J. Sribante, I. Havlik, J. Lipman and D. W. Johnson, "Hydrocorisone and Tumor Necrosis Factor in Severe Community-Acquired Pneumonia: A Randomized Controlled Study," Chest, Vol. 104, No. 2, 1993, pp. 389-392. doi:10.1378/chest.104.2.389

[44] C. Monton, S. Ewig, A. Torres, M. El-Ebiary, X. Filella, A. Rano and A. Xaubet, "Role of Glucocorticoids on Inflammatory Response in Nonimmunosuppressed Patients with Pneumonia: A Pilot Study," European Respiratory Journal, Vol. 14, No. 1, 1999, pp. 218-220. doi:10.1034/j.1399-3003.1999.14a37.x

[45] K. Mikami, M. Suzuki, H. Kitagawa, M. Kawakami, N. Hirota, H. Yamaguchi, O. Narumoto, Y. Kichikawa, M. Kawai, H. Tashimo, H. Arai, T. Horiuchi and Y. Sakamoto, "Efficacy of Corticosteroids in the Treatment of Community-Acquired Pneumonia Requiring Hospitalization," Annals of International Medicine, Vol. 141, 2006, pp. 47-56.

[46] D. Snijders, M. Johannes, A. Daniels, S. Casper, S. De Graaff, S. Tjip, F. Van der Wer, G. Wim and A. Boersma, "Efficacy of Corticosteroids in Community-acquired Pneumonia," American Journal of Respiratory and Critical Care Medicine, Vol. 181, No. 9, 2010, pp. 975-982. doi:10.1164/rccm.200905-08080C

[47] C. L. Sprung, D. Annane, D. Keh, R. Moreno, M. Singer, K. Freivogel, Y. G. Weiss, J. Benbenishty, A. Kalenka, H. Forst, P. F. Laterre, K. Reinhart, B. H. Cuthbertson, D. Payen and J. Briegel, "Hydrocortisone Therapy for Patients with Septic Shock," New England Journal of Medicine, Vol. 358, No. 2, 2008, pp. 111-124. doi:10.1056/NEJMoa071366

[48] D. Annane, E. Bellissant, P. E. Bollaert, J. Briegel, D. Keh and Y. Kupfer, "Corticosteroids for Severe Sepsis and Septic Shock: A Systematic Review and MetaAnalysis," British Medical Association Journal, Vol. 329, No. 7464, 2004, pp. 480-488.

[49] K. P. Steinberg, L. D. Hudson, R. B. Goodman, et al., "Efficacy and Safety of Corticosteroids for Persistent Acute Respiratory Distress Syndrome," New England Journal of Medicine, Vol. 354, No. 16, 2006, pp. 16711684.

[50] B. De Jonghe, T. Sharshar, J. P. Lefaucheur, et al., "Paresis Acquired in the Intensive Care Unit: A Prospective Multicenter Study," Journal of the American Medical Association, Vol. 288, No. 22, 2002, pp. 2859-2867. doi:10.1001/jama.288.22.2859 